\title{
HUMANISTIC FOUNDATIONS OF FOREIGN LANGUAGE EDUCATION: THEORY AND PRACTICE
}

\author{
Svitlana Fedorenko \\ National Technical University of Ukraine "Igor Sikorsky Kyiv Polytechnic Institute", \\ Kyiv, Ukraine \\ 4me@ukr.net
}

\begin{abstract}
The paper focuses on the theoretical analysis of psychological and pedagogic foundations of humanistic foreign language education viewed as an interrelated subject-subject system for improving the emotional and intellectual spheres of students' personal development, which is based on an attitude of interest in life in all its manifestations. Synthesising findings of ethics of care and dialogical pedagogy, humanistic foreign language education is intended to acquaint students with sociocultural knowledge accumulated by humanity; promote better self-understanding and awareness of their place and role in society; develop the ability to adequately assess the possibilities for their self-realisation; teach students to think independently and critically, and to communicate in a civilized and effective way with other people and the world at large. The study of the U.S. practical experience in this educational sphere is highlighted as well. The paper outlines pedagogical participatory techniques, such as role-playing and discussion. They effectively combine the humanistic approach to the educational process with the foreign language study, providing self-discovery and self-perfection. Students are trained as informed and competent interlocutors in the foreign language. They are also educated to reflect on the world through the lens of another culture. The research shows that humanistic foreign language education with its emphasis on the inner world of the learners, their individual thoughts, emotions and feelings is of great significance in overall personality development. Humanistic foundations of pedagogical participatory techniques involve students' affective experiences reflected in the values and ideals that they hold most dear, the meaning and purpose of their lives, their connectedness to each other and to the surrounding world.
\end{abstract}

Keywords: humanistic approach; foreign language education; discussion; dialogical pedagogy; ethics of care; intercultural knowledge; role-playing.

\section{Introduction}

Nowadays, we can observe dynamic intensification of globalisation and integration processes as well as the strengthening of international relations in the world. Modern world overwhelmingly recognises the importance of foreign languages in business, military alliances and in ensuring a world-class education. More and more today's businesses are in dire need of employees who are able to communicate in different languages and comprehend and appreciate other cultures. There appears a need for specialists with foreign language expertise, who are able to successfully communicate with people of other cultures' and to effectively solve problems in their professional activities which demand intercultural knowledge. Moreover, foreign language education can improve individuals' analytic and interpretive capacities. Learning about other cultures will help young people expand their personal horizons and become responsible citizens. No matter what career young people choose, if they have learned a second language, they will have a real advantage.

Furthermore, humanistic orientations in foreign language education contributing to every student's personality wholeness are gaining more and more importance in the twenty-first century. The processes of exploring, understanding and interpreting various sociocultural events, situations etc. are important in the life of young people encouraging them to reflect on the meaning of life, their place and role in the world through generalising and organising their own experiences.

Pointing up the topicality of the humanistic vector of the development of modern society, Toulmin (1990) argues that reconsidering humanism is the main feature of today's mode of thinking. In addition, Adams (1991) emphasises the need for encouraging a person to think in a humanistic way. In his opinion, specialists of all branches of knowledge must think humanely about ways to solve problems (Adams, 1991, p. 284). The scholar also notes that in the intellectual sphere (education, in particular), a purely scientific approach is less objective than a humanistic one in relation to many aspects of life (Adams, 1991, p. 285).

Additionally, Combs (1981) relates to humanism as a systematic deliberate attempt which puts all that is best known to people about their nature and their ability to learn into practice. The U.S. educator is convinced of the viability and efficiency of humanistic tendencies in modern education. In his opinion, the future requires the orientation of the educational process to the "inner world" of the individual, which manifests itself in values, self-esteem and emotions, and taking into account the personal experience of every student (Combs, 1981).

Thus, the humanistic approach as a distinct branch of psychology has been successfully applied to both the theory and practice of education, which, in its turn, contributes to exploiting humanistic concepts in language teaching, foreign one in particular. Stevick (1990) indicates two key principles that underpin 
today's humanistic foreign language teaching: focus on the cognitive and affective aspects of learning; enabling students to reach self-realisation.

Therefore, the aim of the paper is to give a deeper insight into the issue of humanistic foreign language education. The main objectives are as follows: to study psychological and pedagogic foundations of humanistic foreign language education; to highlight some techniques from the U. S. pedagogical experience which provide students with intercultural knowledge and sociocultural knowledge accumulated by humanity as well contributing to their overall personality development.

\section{Methods}

The research design for this study is analytical and descriptive, which places emphasis on a deductivenarrative approach and complex of complementary theoretical methods: critical analysis of philosophical, psychological and pedagogical sources on the research issue; conceptual analysis of the notion "humanistic foreign language education"; study of the pedagogical experience and generalisation on the research problem; monographic method - to interpret the results obtained in a coherent logical perspective.

The study is underpinned by the theory of constructivism (Olusegun, 2015; Merriam, \& Caffarella, 1999; Perkins, 1991; Roth, 2000) - the assimilation of both behaviourism and cognitive ideals, which served as a basis for humanistic education; and the theory of communities of practice (Wenger, 1998) emerged in the field of education at the end of the twentieth century providing the understanding of humanistic foreign language education from a sociocultural perspective. These theories reflect the view that "constructivist stance maintains that learning is a process of constructing meaning; it is how people make sense of their experience" (Merriam, \& Caffarella, 1999, p. 260). Additionally, the research has exploited the idea that the roots of students' knowledge are found in their interactions with the surrounding world and other people before their knowledge is internalised (Roth, 2000).

\section{The theoretical backgrounds of humanistic foreign language education}

Humanistic foreign language teaching in the settings of higher education institutions is grounded on friendly relationships built on mutual respect, trust and care - ethics of care (Noddings, 2003; Nussbaum, 1997); where effective learning often presupposes sharing ideas in communicative interactional practices - dialogical pedagogy (Burbules, 1993; Freire, 2005). In this regard, Stevick (1990) remarks: "in a language course, success depends less on materials, techniques and linguistic analyses, and more on what goes on inside and between the people in the classroom" (p. 4). Sharing Stevick's view, Leadbeater (2008) stresses that students successfully accomplish the outcomes of learning when they are supported by friendly relationships that stimulate motivation, engagement, care and reward. Such relationships for foreign language learning truly recognise students' personalities. Moreover, for young people, recognition is essential in establishing their sense of identity.

Educators (Burbules, 1993; Noddings, 2003; Nussbaum, 1997; Toulmin, 1990) raise the issue of the humanistic revolution in higher education, foreign language education including, which is caused by the "revival" of dialogical pedagogy with its main means of education - a dialogue. As Burbules (1993) rightly points out, a dialogue is an activity aimed at discovering and understanding: it is a constant communicative interaction that promotes a deeper understanding of the world, of self, and of other people (p. 8).

Freire (2005) held the view that for real humanism there is no other way than dialogue - the commitment of a person to constant transformation of reality. Dialogue is friendly relationships which, through the mediation of the world, "proclaim" this world. Together with the transformations, relationships make the world at large humane. It is through dialogue that the spread of humanistic ideas to the learning process takes place and the connection of educational practices to life is intensified. Dialogue is an interaction that determines the effectiveness of communication by taking into account the identity of communicants as well as the differences and originality of their views (Burbules, 1993; Freire, 2005).

As noted by Freire (2005), the characteristics of humanistic education are as follows: participatory learning "tuning in" to the vocabulary universe of the people; educators' laborious search for more productive words at two levels: syllabic richness and experiential involvement; the first codification of those words into visual images which stimulate students "submerged" in the culture of silence to "merge" as conscious creators of their own "culture"; the decodification by a "culture circle" under the teacherfacilitator's stimulus; a creative new codification aimed at action encouraging students to become "subjects" of their own destiny.

The humanistic context of foreign language education involves applying to the dialogue as a process of oral communication; an analysis of specific human actions and deeds (e.g. moral and ethical dilemmas of everyday life); an analysis of certain cultural and historical events of social life with the view to taking into account the moral and ethical aspects of their results (Toulmin, 1990, p. 34). 
Given the above mentioned, it should be noted that humanistic foreign language education as an ongoing process of identity-building and personality transformation where feelings, values, and previous ideas etc. are of great significance.

\section{Pedagogical techniques in the U. S. humanistic foreign language education}

Rooted in constructivist social perspective, humanistic foreign language education allows practising new competencies of collaboration and communication. In that way, teachers are supposed to provide students with a real challenge. Pedagogical techniques putting this aim into practice include discussions on various sociocultural topics, role-playing, public speaking contest, and so on. They bring out students' interest and motivation. Turning to a natural conversation in a free-flowing style, giving and justifying opinions in a foreign language are sure to encourage students' critical thinking as well as a sense of accomplishment. Everybody takes responsibility as an individual and as a group member, striving for the best possible learning outcomes for each participant and for the group as a whole. In such a participatory educational process, the conception of foreign language learning is a wider construct than just the acquisition of knowledge or changing one's behaviour. In addition to acquiring new knowledge and skills, students also get a new way of understanding themselves as personalities.

I would like to share a few humanistically oriented pedagogical techniques and teaching ideas borrowed from the experience of the U. S. educators. This borrowing is explained by the fact that the USA has one of the most advanced traditions of students' communicative training which involves mastering the art of writing and proclaiming not only public speeches but also essays of various socio-cultural themes. At the same time, students study classical political and legal texts closely linked to the high democratic culture of American society, and read and discuss classical works from various fields of knowledge.

One of the techniques adopted from the U.S. experience is a class discussion exploring great ideas of the humankind suggested by Adler \& Hutchins (1990). Such discussions convey the significance of appreciating the complexity of language, embracing different societies' and cultures' perspectives, understanding the specific context of a concept or discourse, cultivating being an informed citizen of the world. In our teaching practice, we have turned to the in-depth consideration of the six great ideas, such as truth, goodness, beauty - the ideas we judge by; and liberty, equality, justice - the ideas we act on. Participating in class, students are engaged in shaping and assessing the ideas, objections, critiques, etc. Before classes, they are assigned to have read the certain material and should be prepared to comment on, put questions, and give opinions on the contributions of other students.

Since discussion as a method of education is based on a dialogue and a polylogue, in which information is transformed into personally vital senses, it requires a responsible attitude not only to the choice of topics, teaching material, the posing of questions but also to its organisation. Therefore, regarding the procedural aspect of any discussion, the suggested scheme is as follows:

1. Making and substantiating the essence of the problem for discussion.

2. Deployment of the topic with indication of ways to solve the problem in the context of its adequate understanding.

3. Critical analysis of the above methods of solving the problem.

4. Reflective and final review of the topic and the outline of new problems that have become more acute or have emerged during the discussion.

To organise an effective discussion we follow the principles of humanistic education, among which:

1) the principle of humane relations between teachers and students, which is based on creating an atmosphere of trust, mutual respect, through which everyone can express themselves, reveal their capabilities; and ensures the development of initiative, creative abilities of the participants;

2) the principle of collaboration and stimulation of subjectivity of students, which ensures creative productive interaction of all participants in the discussion;

3 ) the principle of an individual approach, which involves taking into account each and every student's individual singularity, interests and abilities;

4) the principle of constant updating, which presupposes considering the latest pedagogical technologies, techniques and technological achievements of mankind;

5) the principle of dialogic activity and critical thinking, which embraces the inclusion of each student into the world of deployed meanings, creating opportunities for personal perfection, for the development of every student's internal dialogue as a mechanism of thinking as well as the adherence to the cultural values;

6) the principle of participatory problem-based learning, which assumes students to learn to solve real problems by asking questions, analysing problems, conducting investigations, interpreting, explaining, making judgments and drawing conclusions (Marx et al., 2004). Problem-based learning addresses such 
students' skills as critical and creative thinking, autonomy, metacognitive and communicative skills (HmeloSilver, Duncan, \& Chinn, 2007).

Another pedagogical technique from the findings of the U.S. higher education is role-playing "Reacting to the Past" which takes students into the past providing engagement with great ideas of humanity. Students assuming roles must adhere to the attitudes and values of the historical figures they are assigned to play; they should plan and frame their own means of presenting those historical figures (e.g. through different public presentations). "Reacting to the Past" is an award-winning set of role-playing games that engage students in their own active learning process in the course of which they practice critical and creative thinking, and argument, both written and spoken (Barnard College Reacting Consortium, 2004).

The games "Reacting to the Past" were originally introduced in 1995 by the U. S. historian and educator Dr Mark Carnes. Subsequently, under the auspices of Barnard College and with the support of the Teagle Foundation and the U.S. Department of Education, its methodological support was developed. In 2001 the set of role-playing games "Reacting to the Past" was honoured with the 2004 Theodore Hesburgh Award for outstanding innovation in higher education (Barnard College Reacting Consortium, 2004).

The "Reacting to the Past" games are designed to reflect the multiple causal forces that shape the sociocultural context of human life. According to Proctor (2013), the "Reacting to the Past" games comprise: "real historical setting; rich texts; multiple meetings; roles with well-developed characters; victory objectives; intellectual collisions; indeterminacy; reading, writing, and speaking; narrative structure with drama; possibilities for alternate historical outcomes; accessibility to non-specialists" (p. 10).

The "Reacting to the Past" pedagogy can be built into any course, that of a foreign language one as well. By playing games in the "Reacting to the Past" series, students enhance their communicative, criticalthinking, problem-solving, leadership, and teamwork skills. Class sessions are run entirely by students, while instructors guide students and grade their work.

The "Reacting to the Past" games usually embrace five or six stages and last a few class sessions. During the first session of a game, known as the set-up phase, the instructor lectures on the historical context and gives students assignments on reading major texts and discussing intellectual issues of the game. This session is much like a traditional class, consisting of short reports by students and instructor-directed discussion. In the course of the second or third set-up class, the instructor assigns the roles and students break into groups for effective team-working. Within groups, students are also supposed to meet regularly after classes to accomplish their objectives (Barnard College Reacting Consortium, 2010b).

By the fourth or fifth session, the game phase begins. Students who perform supervisory roles - for example, as president of the Athenian Assembly - are in charge of the proceedings of the game. The instructor should sit in the back of the classroom, intruding only to solve any problems which may arise. And the instructor allocates the time when the game should be over. Then follows the "post-mortem" phase, in which students analyse their performance, discuss the proceedings of the game and determine winners (Barnard College Reacting Consortium, 2010b).

As an example of the Reacting to the Past role-playing game, we consider the game "Greenwich Village, 1913: Suffrage, Labor, and the New Woman" worked out by Mary J. Treacy, Professor of Modern Languages and Literatures, and Director of the Honors Program at Simmons College. This Reacting to the Past game gets students to the turn of the twentieth century, the era of industrialisation and massive immigration in the USA, which greatly influenced the American way of life. The classroom becomes Greenwich Village in 1913, where "free spirits" meet and discuss sociocultural issues. The main characters of the game are suffragists demanding a constitutional vote and asking for the women's place in society. Exposed to ideas like woman suffrage, students experiment with forms of democratic participation and personal self-discovery (Treacy, 2015).

Another example is the game "Acid Rain and the European Environment, 1979-89" designed by David E. Henderson, Professor of Environmental Science at Trinity College, and Susan K. Henderson, Professor of Chemistry at Quinnipiac University. In this role-playing game, students act as representatives of the European nations at some important international conferences from 1979 to 1989 held under the auspices of the United Nations in different cities. The aim of these conferences is to negotiate the first major international treaties on pollution. Students are supposed to deal with environmental issues such as ozone depleting chemicals, transport air pollution and global warming on the basis of critical analysis of the political discourse of that time. The ten-year span of the game gives a rich context for discussions and debates in which economic, scientific and ethical aspects of the environmental problems are covered. Students get to know that in 1972 the UN adopted the treaty according to which nations bear responsibility for the effects of pollution outside their borders. Later on, the transport air pollution treaty was proposed against the background of forming the European Union and the start of Détente between the Soviet Union 
and the West. Students become mindful of the political ideologies and pressures put on negotiators during this period. Then follows the final phase, in which students freely discuss the results of the game as well as current environmental concerns and some harmful human activities on the biophysical environment (Barnard College Reacting Consortium, 2010a).

In view of the above, we may note that the effective use of participatory pedagogical techniques depends on how their content and form will interest students, influence their perception of the world, promote self-development and, therefore, comply with the following principles: emotional response as a prerequisite for the direct involvement of students in the process of active interaction; the use of associative connections based on the past acquired experience; the development of cognitive interest, which provides a constant expansion of the outlook of every student; personal interpretation of educational situations; selfimprovement as a result of conscious and purposeful spiritual communication and knowledge of oneself and the world at large through dialogue; self-reflection and self-regulation, which is evidence of students' spiritual, moral and ethical maturity.

\section{Conclusions}

In consequence we conclude, the above-mentioned humanistically oriented pedagogical techniques contribute to favourable conditions for the manifestation of individuality, independence in expressing views on a particular issue, in forming the ability to successfully interact with others, to listen and to hear others, to respect their beliefs, to correlate and coordinate their own views with the views of other participants. In addition, the above-mentioned techniques are instrumental in students' intellectual development by increasing their interest in a variety of subjects, helping to clarify their values and attitudes. The techniques outlined above provide feedback on students' acquisition of knowledge through questions, comments, elaborations and justifications. These interactions allow seeing the depths of students' understanding of the world at large. We believe that this will have its continuation in different spheres of students' life, contributing to their active inclusion in constructive interpersonal and intercultural dialogue.

And finally, developing knowledge of a foreign language and culture contributes to expanding one's personality, acquiring options that are both life-enriching and liberating

In the context of the problem under study, the scope of further research envisages exploring the experience of the European educators in the sphere of humanistic foreign language teaching with the view to considering the prospective ways of borrowing their progressive ideas into the educational environment of Ukraine.

\section{References:}

Adams, E. M. (1991). Metaphysics of Self and World: Toward a Humanistic Philosophy. Philadelphia: Temple University Press. Adler, M. J., \& Hutchins, R. (1990). A Syntopicon: An Index to the Great Ideas. New York: Encyclopaedia Britannica, Inc.

Barnard College Reacting Consortium (2004). Reacting to the Past. Retrieved 28 August, 2018 from http://reacting.barnard.edu/

Barnard College Reacting Consortium (2010a). Reacting to the Past: Acid Rain and the European Environment, 1979-89. Retrieved 28 August, 2018 from https://reacting.barnard.edu/acid-rain-and-european-environment-1979-89

Barnard College Reacting Consortium (2010b). Reacting to the Past: Pedagogical Introduction. Retrieved 28 August, 2018 from http://reacting.barnard.edu/sites/default/files/inline/reacting_pedagogical_introduction-9-20-2010.pdf

Burbules, N. (1993). Dialogue in Teaching: Theory and practice. New York: Teachers College Press.

Combs, A. W. (1981). Humanistic Education: Too Tender For a Tough world? Phi Dielta Kappa, 62(6), 446-449.

Freire, P. (2005).Education for critical consciousness. New York: Continuum.

Hmelo-Silver, C. E. (2004). Problem-based learning: What and how do students learn? Educational Psychology Review, 16(3), $235-266$.

Leadbeater, C. (2008). We think: Mass innovation, not mass production. London, UK: Profile.

Marx, R. W., Blumenfeld, P. C., Krajcik, J. S., Fishman, B., Soloway, E., Geier, R., \& Tal R. T. (2004). Inquiry-based science in the middle grades: Assessment of learning in urban systemic reform. Journal of Research in Science Teaching, 41(10), 1063-1080.

Merriam, S., \& Caffarella, R. (1999). Learning in Adulthood: A Comprehensive Guide. San Francisco: Jossey-Bass.

Noddings, N. (2003). Caring: A Feminine Approach to Ethics and Moral Education. Berkeley: University of California Press.

Nussbaum, M. (1997). Cultivating Humanity: A Classical Defense of Reform in Liberal Education. Cambridge, Massachusetts, \& London: Harvard University Press.

Olusegun, B. S. (2015). Constructivism Learning Theory: A Paradigm for Teaching and Learning. Journal of Research \& Method in Education, 5(6), 66-70.

Perkins, D. N. (1991). What constructivism demands of the learner. Educational technology, 31(10), 19-21.

Proctor, N. W. (2013). Reacting to the Past: Game Designer's Handbook. Simpson College.

Roth, W. M. (2000). Learning environments research, lifeworld analysis, and solidarity in practice. Learning Environments Research, 2, 225-247.

Stevick, E. W. (1990). Humanism in Language Teaching: A Critical Perspective. Oxford: Oxford University Press.

Toulmin, S. (1990). Cosmopolis: The Hidden Agenda of Modernity. New York: Free Press

Treacy, M. J. (2015). Greenwich Village, 1913: Suffrage, Labor, and the New Woman. New York: W.W. Norton \& Company.

Wenger, E. (1998). Communities of practice: learning, meaning, and identity. Cambridge: Cambridge University Press. 